\title{
Otorhinolaryngology, Head and Neck Surgery Services in Khartoum State in Sudan 2015
}

\author{
Dr. Malik Ibrahim Malik ${ }^{1}$, Dr. Sharfi Abdelgadir Omer Ahmed ${ }^{* 2}$, Dr. Muna Ahmed Abdulrahim ${ }^{3}$ \\ ${ }^{1}$ MBBS, Lecturer at faculty of Medicine, Omdurman Islamic University \\ ${ }^{2}$ Associated Professor, Dean Faculty of Medicine, Omdurman Islamic University \\ MBBS, MD ORL-Sudan, DOHNS London \\ ${ }^{3}$ Assistant Professor, faculty of Medicine EINielin University Consultant Otolaryngologist, MD, ORL-Sudan
}

\section{Abstract:}

Background: In Khartoum state, formal health services are heavily centralized. This is reflected by a specialist services coverage that is double the national ratio in Sudan, as is the case for other health services and cadres.

Objectives: The aim of this study to establishment a database for ENT, audiology and speech therapy services in Khartoum state.

Methods: This is descriptive, cross-sectional study hospital based. Include all Hospitals that provide otorhinolaryngological, head and neck surgery services within Khartoum state.

Results: Total numbers of hospitals included in this study were 16 hospitals and departments providing otorhinolaryngological services in Khartoum state. General hospitals that contain ENT departments were 13 hospitals (81.25\%) and hospitals that specialized for otorhinolaryngological services were three hospitals (18.75\%).

Conclusion: Otorhinolaryngological hospitals are distributed within Khartoum state with inequality to proportion of populations within provinces, also there is great deficiency on audiology and speech therapy services with variable distribution.

Keywords: Otorhinolaryngology, Health services, Khartoum state.

\section{Introduction and Literature review}

The specialty of otorhinolaryngology is a product of the early 20th century for it was then it was separated fields of otology and laryngology and then joined together for separate ${ }^{(1,2)}$.

In the sphere of rhinology, a greater understanding of immunology and the function of the nose has expanded the knowledge of rhinitis and led to more conservative nasal surgery and complications of sinus infection have become rare ${ }^{(2)}$.

Audiology has become a specialty in its own right and the sophisticated tests of hearing and balance, together with the provision of investigation and treatment of deaf children and elderly people, are managed by audio logical physicians.
There are wide distribution of health services between Khartoum and peripheries with total $28,165 \mathrm{~km}$. The Khartoum state composed from 7 provinces with total number of populations is 6.188 .222 inhabitants in 2014 which with $81 \%$ of them are urban. There are12 general hospitals and 22 specialized hospital and 14 rural hospitals. Regarding private sector, there are 157 general hospitals, one police hospital and 22 specialized private hospitals. Regarding there distribution 10 hospitals are in Khartoum, 8 hospitals in Omdurman and two hospitals in Bahri ${ }^{(1,2, \text { and } 3)}$.

There is 6,529 beds in Khartoum state that equal (22.58\%) from total beds in Sudan. Total number of beds for otorhinolaryngology services there are 287beds in Sudan, the Khartoum state has 104 that represents $(36.23 \%)$ from the total number of beds in Sudan ${ }^{(1,3)}$. 


\section{International Journal of Innovative Research in Medical Sciences (IJIRMS) \\ ISSN (Online): 2455-8737, Vol. 01, Issue 06, August 2016 \\ Available online at $-w w w . i j i r m s . i n$}

The total number of ENT surgeons in 2008 and 2009 were 51 doctors and the number increased to 64 in 2010 and 66 in 2011 and then decreased to 65 doctors in 2012. In 2014, the total numbers of ENT surgeons were 25. In 2012 total number of surgical operations done in Khartoum state 5773 which represents $55.31 \%$ of total otorhinolaryngology operations in Sudan ${ }^{(2,}$ ${ }^{4)}$.The main functions of an out-patient department in ENT services are as follows: provide specialist consultation and conduct appropriate examination ${ }^{(4)}$.

Hussian et al concluded that minimal requirements for the outpatients include flexible nasopharyngescope equipment, head light, tongue depressors, fine needle aspiration and true-cut biopsy equipments in laryngology field. Flexible nasopharyngescope with stroboscopy video capture in voice clinic and rigid laryngoscope for voice assessment in the voice clinic. Rigid nasal endoscopy with high definition endoscope camera, nasal speculae, biopsy instruments, cautery equipment, nasal packs and associated equipment, endoscope cameras and access to medical photography equipment for rhinology and facial plastic surgery clinic. Otoscopes, microscope, otoendoscopes, aural speculae suction and other aural instruments and tuning forks in the otology department. All these are important equipments to be available in every ENT department ${ }^{(5)}$.

Endoscopic nasal surgery is now the mainstay of intervention for many sinonasal and skull base conditions and indeed one of the most frequently performed ENT procedures, and its success has prompted rapid development of innovative techniques and technology over the last two decades, including its extension of application to skull base surgery and orbital procedures ${ }^{(7,8)}$.

Cryotherapy is the application of temperatures below freezing point to tissues, resulting in injury and subsequent cell death. It was found to be a safe, convenient and can be done under a local anesthetic in the out-patients department ${ }^{(9)}$.

Since 1971 the CO2 laser has been used in otolaryngology at Boston University School of Medicine. The advantages of laser surgery in otolaryngology are so significant that it can be recommended for continued usage and many applications of this unique surgical instrument have been identified but others need to be explored in the future ${ }^{(9)}$.

Coblation is a unique method of delivering radio frequency energy to soft tissue for applications in Otolaryngology (ENT). Coblation is currently being tested in various clinical studies to document the benefits for otorhinolaryngological applications ${ }^{(10)}$.

\section{Materials and methods}

\section{Study design:}

Descriptive hospital based cross-sectional study from January 2015 to October 2015.This study was done in Sudan at Khartoum state ENT hospitals and departments.

\section{Inclusion criteria:}

To study all hospitals within Khartoum state that actively enrolling to provide otorhinolaryngological, head and neck surgery services.

\section{Methods of data collection:}

Detailed structured, pretested and pre-coded questionnaire was filled for each hospital respondent after obtaining consent.

\section{Data management and analysis:}

Data analyzed using Statistical Package for Social Science (SPSS) data analysis tool, version 17 and graph charts and table designed by the use of Microsoft Office Excel 2007.

\section{Ethical clearance:}

Obtained from the research and thesis committee at Sudan Medical Specialization Board and research administration at Ministry of Health, Khartoum state.

\section{Results:-}

Total numbers of hospitals included in this study were 16 specialized hospitals and departments providing Otorhinolaryngological services in the Khartoum state. In Khartoum province there was 10 ENT specialized hospitals and departments (62.50\%), three of ENT departments in Bahri and Omdurman provinces $(18.75 \%)$ for each (Figure 1). 


\section{International Journal of Innovative Research in Medical Sciences (IJIRMS) \\ ISSN (Online): 2455-8737, Vol. 01, Issue 06, August 2016 \\ Available online at $-\underline{w w w . i j i r m s . i n}$}

Otorhinolaryngological hospitals and departments in Sudan established early in 1958, then between 1970 to1979 two ENT departments were established. In 1980 to 1989 another two ENT departments were established, from 1990 to 1999 three ENT departments were established, then from 2000 to 20093 ENT departments and new ENT specialized hospital established. From 2010 until now another 3 ENT departments and one new specialized ENT hospital established.

Audiological services perform basic audiological assessment like pure tune audiogram and tympanometry. There were 10 ENT specialized hospitals and departments with no audiological services (62.5\%) and 6 specialized hospitals and departments with presence of this service $(37.5 \%)$ (Figure 2).

Total numbers of voice and speech therapists were two working in the state ENT hospitals and departments. The services were absent in 12 hospitals and departments (75\%) and were available in 4 specialized hospitals and departments (25\%) (Figure 3).

Total numbers of beds were 282 for otorhinolaryngology departments in general departments and specialized hospitals. Beds were available for the ENT service within Khartoum state which shared with other specialties in general hospital werefound in six hospitals $(37.50 \%)$ and were separated from other specialties in 5 general hospitals (31.25\%). Specialized hospitals for otorhinolaryngology were three $(18.75 \%)$ and no beds were available for otorhinolaryngology services in two hospitals (12.50\%) (Table 1).

Table (2) shows out-patients and referral clinics equipment's. Regarding head lamps and mirrors they were available in all ENT specialized hospitals and departments, but rigid endoscopes with different lenses were available in 9 specialized hospitals and departments (56.25\%) and were not available in 7 ENT departments $(43.75 \%)$. Flexible nasopharyngescope was not available in 10 ENT departments (62.50\%) and was available in 6 specialized hospitals and departments (37.50\%). Examination microscope was not available in 11 ENT departments (68.75\%) and was available in 5specialized hospitals and departments (31.25\%).
Regarding modern ENT equipment's in operation rooms', operating endoscopes are not available in 10 ENT departments (62.50\%) and available in 6 specialized hospitals and departments (36.50\%). Operating microscope with 250 lens used for otological surgery was not available in 9 ENT departments $(56.25 \%)$ and was available in 7 hospitals and departments (43.75\%), but operating microscope with 400 lens used for microlaryngeal surgery was not available in 12 ENT departments (75\%) and was available in 4 specialized hospitals and departments (25\%). Regarding FESS instruments like Uni-drive unit (shaver), was not available in 11departments $(68.75 \%)$ and was available in 5 specialized hospitals and departments $(31.25 \%)$. Otology drill was found in 9 specialized hospitals and departments $(56.25 \%)$ and was not available in 7 ENT departments (43.75\%). Cryoprobe used in cryosurgery was not available in 15 specialized hospitals and departments $(93.75 \%)$ and available only in one department $(6.25 \%)$. Regarding the laser was not available in 15 specialized hospitals and departments (93.25\%) and was available in one hospital $(6.25 \%)$. Navigator as modern tool for ENT surgery was not available in all otorhinolaryngology specialized hospitals and departments. Nerve monitorwas not available in 14 specialized hospitals and departments $(87.50 \%)$ and was available in 2 specialized hospitals and departments (12.50\%). Coblator that used in different otorhinolaryngological surgeries, not available in 13 specialized hospitals and departments $(81.25 \%)$ and available in 3 specialized hospitals (18.75\%) (Table 3).

Regarding rigid endoscopes with both sizes for adults and pediatrics used for different otorhinolaryngological procedures, rigid oesophagescope was not available in 9 departments (56.25\%) and was available in 7 specialized hospitals and departments (43.75\%), while rigid bronchoscope was available in 8 specialized hospitals and departments (50\%) and was not available in 8 hospitals and departments (50\%). Direct laryngoscope was available in 9 specialized hospitals and departments $(56.25 \%)$ and was not available in 7 departments $(43.75 \%)$ (Table 4).

Regarding different otorhinolaryngological sets for surgery; adenoidectomy and tonsillectomy sets were found in 15 specialized hospitals and departments 
(93.75\%) and were not available in one ENT department $(6.25 \%)$, while nasal surgery sets were available in 12 specialized hospitals and departments (75\%) and were not available in 4 ENT departments $(25 \%)$. Ear surgery sets were available in 11 specialized hospitals and departments $(68.75 \%)$ and werenot available in 5 ENT departments $(31.25 \%)$, head and neck surgery sets were available in 13 specialized hospitals and departments $(81.25 \%)$ and were not available in 3 ENT departments (18.75\%). Tracheostomy sets were present in 13 specialized hospitals and departments $(81.25 \%)$ and were not available in 3 ENT departments (18.75\%) (Table 5).

Table (1): Availability of beds for ENT services in the Khartoum state hospitals and departments:

\begin{tabular}{|c|c|c|}
\hline ENT beds & Number of hospitals & Percentage \\
\hline Shared with other specialties & 6 & $37.50 \%$ \\
\hline Separated from other specialties & 5 & $31.25 \%$ \\
\hline Specialized ENT hospitals & 3 & $18.75 \%$ \\
\hline No beds available for ENT services & 2 & $12.50 \%$ \\
\hline Total & 16 & $100 \%$ \\
\hline
\end{tabular}

Table (2): Availability of out-patients' and referral clinics equipment's in the Khartoum state ENT specialized hospitals and departments:

\begin{tabular}{|c|c|c|c|}
\hline Equipment's & $\begin{array}{c}\text { Numbers of hospitals and } \\
\text { departments that available in }\end{array}$ & $\begin{array}{c}\text { Numbers of hospitals and } \\
\text { departments not available in }\end{array}$ & Total \\
\hline Head lamp and mirror & 16 & 0 & 16 \\
\hline $\begin{array}{c}\text { Rigid endoscopes with } \\
\text { different lenses }\end{array}$ & 9 & 7 & 16 \\
\hline $\begin{array}{c}\text { Flexible } \\
\text { nasopharyngescopes }\end{array}$ & 6 & 10 & 16 \\
\hline Examination microscopes & 5 & 11 & 16 \\
\hline
\end{tabular}

Table (3): Availability of modern ENT equipment's for ENT services in operation rooms in the Khartoum state hospitals and departments:

\section{Equipment's}

Number of hospitals that

Total equipment were available

\section{equipment were not available}

\begin{tabular}{l|l}
10 & 16
\end{tabular}

Operating endoscope with 0 ,

6

30 and 70 lens

Operating microscope with 200 lens

Operating microscope with 400 lens

Uni-drive unit

Otology drill
7

9

4

5

9
12

11

7 \begin{tabular}{l|l}
10 & 16
\end{tabular} 16

\begin{tabular}{l|l}
9 & 16
\end{tabular}

16

16

16 
International Journal of Innovative Research in Medical Sciences (IJIRMS)

ISSN (Online): 2455-8737, Vol. 01, Issue 06, August 2016

Available online at - www.ijirms.in

\begin{tabular}{|c|c|c|c|}
\hline Cryoprobe & 1 & 15 & 16 \\
\hline Laser & 1 & 15 & 16 \\
\hline Navigator & 0 & 16 & 16 \\
\hline Nerve stimulator monitor & 2 & 14 & 16 \\
\hline Coblator & 1 & 15 & 16 \\
\hline
\end{tabular}

Table (4): Presence of rigid endoscopes with adults and pediatrics sizes in ENT specialized hospitals and departments:

\begin{tabular}{|c|c|c|c|}
\hline Rigid endoscopes & $\begin{array}{c}\text { Number of hospitals that } \\
\text { present }\end{array}$ & $\begin{array}{c}\text { Number of hospitals that } \\
\text { absent }\end{array}$ & Total \\
\hline Esophagoscope & 7 & 9 & 16 \\
& $43.75 \%$ & $56.25 \%$ & $100 \%$ \\
\hline Bronchoscope & 8 & 8 & 16 \\
\hline Direct laryngoscope & $50 \%$ & $50 \%$ & $100 \%$ \\
& 9 & 7 & 16 \\
\hline
\end{tabular}

Table (5): Presence of different otorhinolaryngological sets in the Khartoum state hospitals and departments:

\begin{tabular}{|c|c|c|c|}
\hline Surgical sets & $\begin{array}{r}\text { Number of hospitals that } \\
\text { surgical sets were available }\end{array}$ & $\begin{array}{c}\text { Number of hospitals that surgical sets } \\
\text { were not available }\end{array}$ & Total \\
\hline $\begin{array}{c}\text { Adenoidectomy- } \\
\text { tonsillectomy sets }\end{array}$ & 15 & 1 & 16 \\
\hline Nasal surgery set & $93.75 \%$ & $6.25 \%$ & $100 \%$ \\
\hline Ear surgery set & 12 & 4 & 16 \\
\hline Head and neck & $75 \%$ & $25 \%$ & $160 \%$ \\
\hline surgery set & 11 & 5 & $100 \%$ \\
\hline Tracheostomy set & 13 & $31.25 \%$ & 16 \\
\hline
\end{tabular}


International Journal of Innovative Research in Medical Sciences (IJIRMS)

ISSN (Online): 2455-8737, Vol. 01, Issue 06, August 2016

Available online at $-\underline{w w w . i j i r m s . i n}$

Figure (1): Distribution of ENT specialized hospitals and departments within the Khartoum state:

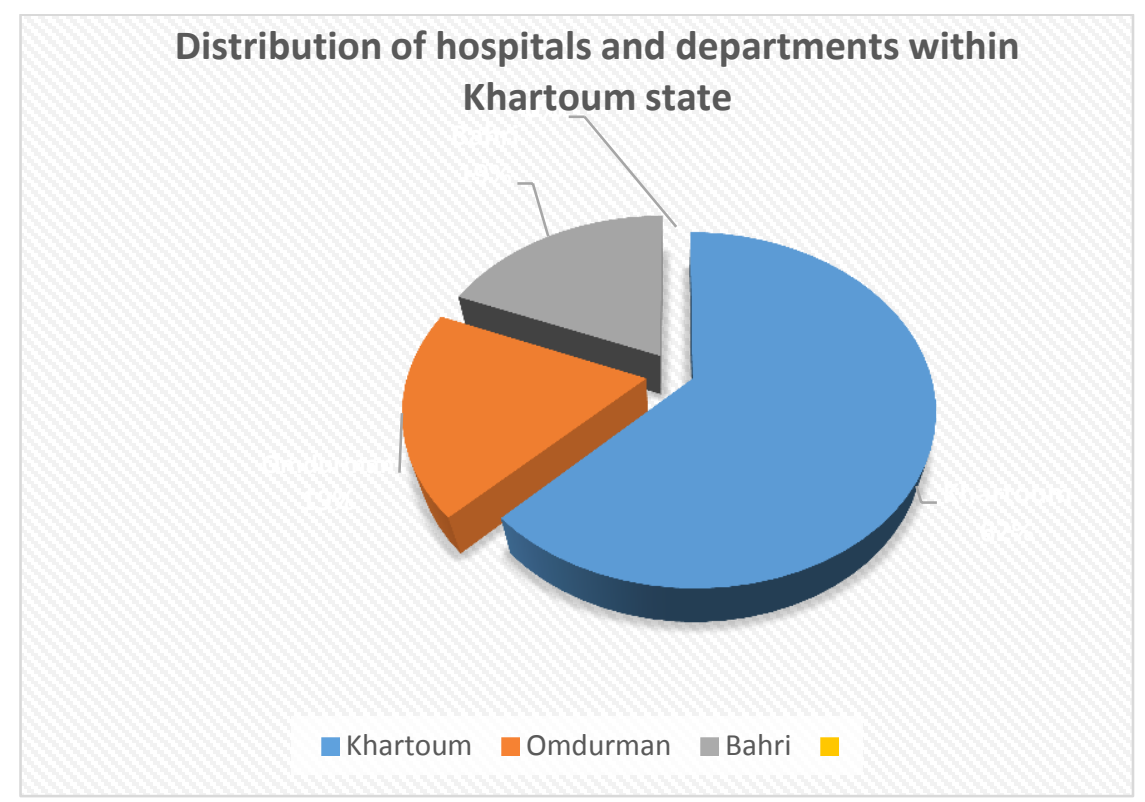

Figure (2): Availability of audiology services in ENT specialized hospitals and departments:

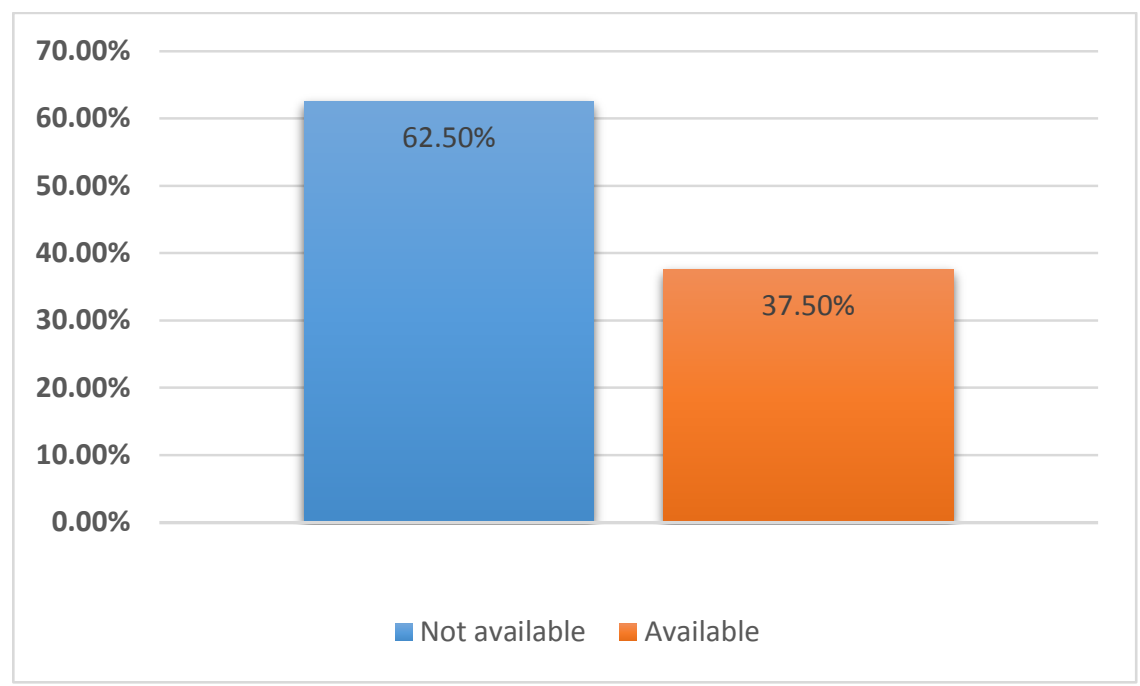

Figure (3): Availability of clinical speech and voice therapy services in ENT specialized hospitals and departments: 


\section{International Journal of Innovative Research in Medical Sciences (IJIRMS) \\ ISSN (Online): 2455-8737, Vol. 01, Issue 06, August 2016 \\ Available online at $-\underline{w w w . i j i r m s . i n}$}

\section{Discussion}

Otorhinolaryngology head and neck specialized hospitals and departments found to be 16 in this study, with total number of ENT departments were 13 within general hospitals and 3 hospitals that they are specialized for Otorhinolaryngological services. Khartoum ENT was the only public specialized hospital for ENT services in the state and represent $(4.54 \%)$ this is give a clue that the services have great shortage in spite of the increasing needs ${ }^{(1)}$.

As Khartoum state has total number of inhabitants are 6.188.222, these inhabitants served by 10 ENT specialized hospitals and departments ${ }^{(3)}$.

Otorhinolaryngology specialty is oldest in Sudan established the services early in 1958 and progress over the time in comparison to Sultanate Oman that the first hospital for ENT started1974 ${ }^{(17)}$.

There were total number of 3 clinical audiologist providing audiological services in the Khartoum state that represent 0.04 for 100000 populations and in South Africa found to be the country has the greatest number of clinical audiologists has 490 clinical audiologists represent 1.021 for 100000 populations. There is great shortage of audiologists that providing audiological services in Khartoum state ${ }^{(12)}$.

There were total number of 2 clinical voice and speech therapists providing these services with 0.03 doctors for 100000 populations that near the ratio of Madagascar and in South Africa there is 1144 voice and speech therapists as the greatest number of voice and speech therapists in Africa with 2.383 for 100000 populations ${ }^{(12)}$.

With regards to requirements of ENT different surgeries in operating theatres, in this study showed that there were variable distribution of different theatres equipment's availability to different ENT surgical procedures in more than 50\% in Khartoum state especially in operating rigid naso-endoscopes with different lenses of $0,30.45$ and 70 , operating microscope with 250 and 400 lens, Uni-drive unit, nerve stimulator monitor and coblator in spite of their great importance in different otorhinolaryngological surgical procedures. Cryoprobe and laser are only found in one hospital and department and navigator is totally absent in all ENT specialized hospitals and departments ${ }^{(6,7)}$.

Rigid endoscopes have great and important role for different diagnostic and treatment purposes and showed availability in more than half of the state hospitals in rigid bronchoscopy and direct laryngoscope and less than half of the availability of rigid esophagoscope ${ }^{(6,7)}$.

In the current study availability of different surgical sets showed there were available in different Khartoum state hospitals reaching more than $75 \%$ availability in adenoidectomy and tonsillectomy sets, nasal surgery sets, head and surgery sets and tracheostomy sets. Ear surgery sets were available in $(68.75 \%)$ in spite otorhinolaryngological hospitals and departments are facing great number of otological diseases ${ }^{(6,7)}$.

\section{References:}

[1] Federal Ministry of Health. The annual statistics health report 2012. Khartoum, Sudan N.p., 2013. Print.

[2] El Tayeb, Sally, et al. "Use of healthcare services by injured people in Khartoum State, Sudan." International health (2014): ihu063.

[3] Ministry of Health, Khartoum state. The annual statistics health report 2014. Khartoum, Sudan N.p., 2015. Print.

[4] NHS Estates. Facilities for surgical procedures. Vol. 1. The Stationery Office, 2004.

[5] Hussain, S. S. M., et al. "On the minimum requirements for otolaryngology clinics in National Health Service hospitals." The Journal of Laryngology \& Otology 129.05 (2015): 494-495.

[6] Fokkens, Wytske J., et al. "EPOS 2012: European position paper on rhinosinusitis and nasal polyps 2012. A summary for otorhinolaryngologists."Rhinology $\quad 50.1$ (2012): 1-12.

[7] Kennedy, David W. "Technical innovations and the evolution of endoscopic sinus surgery." The Annals of otology, rhinology \& laryngology. Supplement 196 (2006): 3-12.

[8] Metson, Ralph, and Steven D. Pletcher. "Endoscopic orbital and optic nerve decompression." Otolaryngologic Clinics of North America 39.3 (2006): 551-561.

[9] Beg, M. H. A., and A. Qayum. "Cryosurgery in Otolaryngology." JPMA. The Journal of the Pakistan Medical Association 32.8 (1982): 183-186. 
[10] Strong MS et al. Transactions. Section on Otolaryngology. American Academy of Ophthalmology and Otolaryngology. 1976, 82(5):595-602.

[11] Al-Khabori, Mazin. "Evolution of ENT services in oman." Oman medical journal23.2 (2008): 65.

[12] Fagan, Johan J., and Marian Jacobs. "Survey of ENT services in Africa: need for a comprehensive intervention." Global Health Action 2 (2009). 